\title{
Combined Atmospheric And Ocean Profiling From an Airborne High SPECTRAL RESOLUTION LIDAR
}

\author{
Johnathan Hair ${ }^{1 *}$, Chris Hostetler ${ }^{1}$, Yongxiang $\mathrm{Hu}^{1}$, Michael Behrenfeld ${ }^{2}$, Carolyn Butler ${ }^{3}$, David \\ Harper $^{1}$, Rich Hare ${ }^{1}$, Timothy Berkoff ${ }^{1}$, Antony Cook ${ }^{1}$, James Collins ${ }^{3}$, Nicole Stockley ${ }^{4}$, Michael \\ Twardowski ${ }^{5}$, Ivona Cetinić ${ }^{6+}$, Richard Ferrare ${ }^{1}$, and Terry Mack
}

${ }^{1}$ NASA Langley Research Center, Hampton VA 23681, USA, *Email: johnathan.w.hair@nasa.gov, ${ }^{2}$ Oregon State University, Corvallis, OR, 97331, USA, ${ }^{3}$ Science Systems and Applications Inc., Hampton, VA 23666, USA, " WET Labs, Inc., Narragansett, RI 02882, ${ }^{4}$ Harbor Branch Oceanographic Institute, Florida Atlantic University, Ft. Pierce, FL 34946, ${ }^{6}$ University of Maine, Walpole, ME 04573, ${ }^{+}$currently NASA Goddard Space Flight Center/USRA, Greenbelt, MD 20771, ${ }^{7}$ Analytical Mechanics Associates, Hampton, VA 23666

\section{ABSTRACT}

First of its kind combined atmospheric and ocean profile data were collected by the recently upgraded NASA Langley Research Center's (LaRC) High Spectral Resolution Lidar (HSRL-1) during the 17 July - 7 August 2014 Ship-Aircraft Bio-Optical Research Experiment (SABOR). This mission sampled over a region that covered the Gulf of Maine, open-ocean near Bermuda, and coastal waters from Virginia to Rhode Island. The HSRL-1 and the Research Scanning Polarimeter from NASA Goddard Institute for Space Studies collected data onboard the NASA LaRC King Air aircraft and flight operations were closely coordinated with the Research Vessel Endeavor that made in situ ocean optical measurements. The lidar measurements provided profiles of atmospheric backscatter and particulate depolarization at $532 \mathrm{~nm}, 1064 \mathrm{~nm}$, and extinction $(532 \mathrm{~nm})$ from approximately $9 \mathrm{~km}$ altitude. In addition, for the first time HSRL seawater backscatter, depolarization, and diffuse attenuation data at $532 \mathrm{~nm}$ were collected and compared to both the ship measurements and the Moderate Resolution Imaging Spectrometer (NASA MODIS-Aqua) satellite ocean retrievals.

\section{INTRODUCTION}

A combined ocean and atmospheric lidar has the potential to provide key measurements needed to better understand both the ocean optical properties, and hence the biogeochemical properties of the global oceans, and air-sea exchange processes important for climate studies. For example, it has been shown that the particle organic carbon stocks in the ocean are better estimated from particle backscatter than chlorophyll concentrations [e.g. 1]. In addition, lidar has the ability to provide vertical distributions of the optical properties within the ocean that are not possible from current passive satellite measurements. Recent results using the CALIPSO satellite measurements have revealed that global measurements [2] of vertically integrated backscatter within the ocean are possible, even from an instrument not designed for ocean profiling. As noted in [2], using the High Spectral Resolution Lidar and a passive ocean color sensor could result in a 3-D distribution of the upper ocean ecosystem.

To demonstrate the quantitative capabilities of such a system, the airborne HSRL that has flown on the King Air aircraft during many field campaign since 2006 [3] was recently configured to provide high vertical profiling to 3 optical depths below the ocean surface. The atmospheric HSRL measurements have been compared to both in situ and other remote sensors [5] and continues to provide key validation data for CALIOP sensor on the CALIPSO satellite [6].

\section{METHODOLOGY}

The HSRL technique relies on the difference between the spectral distributions of $180^{\circ}$ backscatter from particles and molecules [2]: backscatter from particles (e.g., plankton or atmospheric aerosols) is at the same frequency as the transmitted laser pulse, whereas molecular backscatter is shifted in frequency. The basic diagram of the lidar system is provided in Fig 1A. As shown, an iodine vapor cell functions as a spectral filter in the receiver and frequency discrimination is achieved by tuning the narrowband laser to an absorption line of the iodine gas. The spectral distribution of the backscatter is shown in Fig. 1B for both the atmosphere and the ocean. The Co-polarized and Cross-polarized Channels measure both molecular 
and particulate backscatter, while the Molecular Channel measures only the molecular backscatter. Backscatter from water molecules in the ocean (blue) is dominated by Brillouin scattering, which is shifted both up and down in frequency from the source laser by $\sim 7-8 \mathrm{GHz}$ while backscatter from air molecules (red) is both Brillouin and Doppler shifted (Cabannes) scattering, resulting in broadening of about $3 \mathrm{GHz}$. Molecular scattering is therefore transmitted by the iodine vapor filter, the shaded regions shown in Fig. 1B, while backscatter from particles in the atmosphere and ocean is effectively blocked. The choice of the particular iodine line can be configured such that the ocean Brillouin scattering is insensitive to changes due to changes in ocean temperature and salinity.
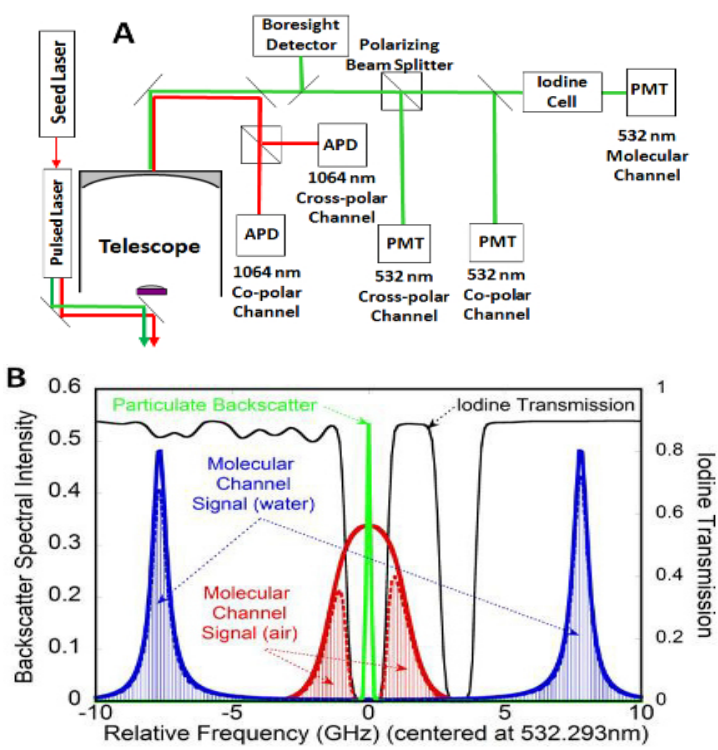

Figure 1. (A) Block diagram of the HSRL-1 instrument and (B) the spectra of backscatter signals at $532 \mathrm{~nm}$ relative to the iodine vapor filter absorption features.

The instrument, measurement technique, and calibration methods for the HSRL instrument are outlined in [3] for the atmospheric measurements and are performed similarly for the ocean measurements. As noted above, the instrument was recently upgraded to provide high resolution sampling of the ocean from near the surface to approximately three optical depths $(40-45 \mathrm{~m}$ in the open clear ocean) at a resolution of $1 \mathrm{~m}$ in the ocean (120MHz sampling). New detection electronics were developed along with integrating new Hybrid Photodetectors (HPD) to reduce the effects of after-pulsing. In addition, the laser was upgraded to narrow the pulse width (6ns) and increase the pulse repetition rate $(4000 \mathrm{~Hz})$ with slightly higher energies $(2.5 \mathrm{~mJ})$.

\section{RESULTS}

During SABOR we conducted 24 science flights split evenly between bases in Portsmouth NH, St. George's Bermuda, and Hampton, VA onboard the NASA LaRC King Air aircraft which flew at an altitude of $8-9 \mathrm{~km}$. The flights included overpasses of the RV Endeavor research vessel during the campaign, thus providing coordinated measurements made remotely and in situ of the seawater.

The flight track of the first science flight on 18 July 2014 is shown in Fig. 2 (inset); the track is color-coded with aerosol optical depth (532nm). The combined atmosphere and ocean backscatter for the region in the highlighted red box is also shown. This segment shows a region that covered a large dynamic range in aerosol optical depth $(\sim 0.04-0.14)$ and a large dynamic range in the particulate backscatter in the ocean $\left(0.3-16.7 \mathrm{~km}^{-}\right.$ $\left.{ }^{1} \mathrm{sr}^{-1}\right)$. Note that the altitude scale for the atmosphere is in kilometers and meters for the ocean. The large atmospheric backscatter above $4 \mathrm{~km}$ in the northern portion of the flight was dominated by smoke advected into this region from forest fires in the Western US. This condition was prevalent during most of the flights conducted from Portsmouth NH. This provides an ideal case to compare the atmospheric corrections required for the ocean color retrievals from MODIS (AQUA satellite) and VIIRS (NPP satellite). Also note that the backscatter in the ocean increases around 19UT as the flight track approaches the George's Bank region off the coast of Massachusetts, which is known for high phytoplankton stocks and productivity. The Gulf of Maine also has higher backscatter values that vary with depth compared to the open ocean.

This particular flight also offered a first-of-kind opportunity to compare airborne lidar data with satellite retrievals of the ocean optical properties. It is expected that for the flight altitude and instrument parameters, the lidar attenuation is approximately equal to the exponential decrease of the downwelling irradiance with depth, known as the diffuse attenuation coefficient [8], which is 


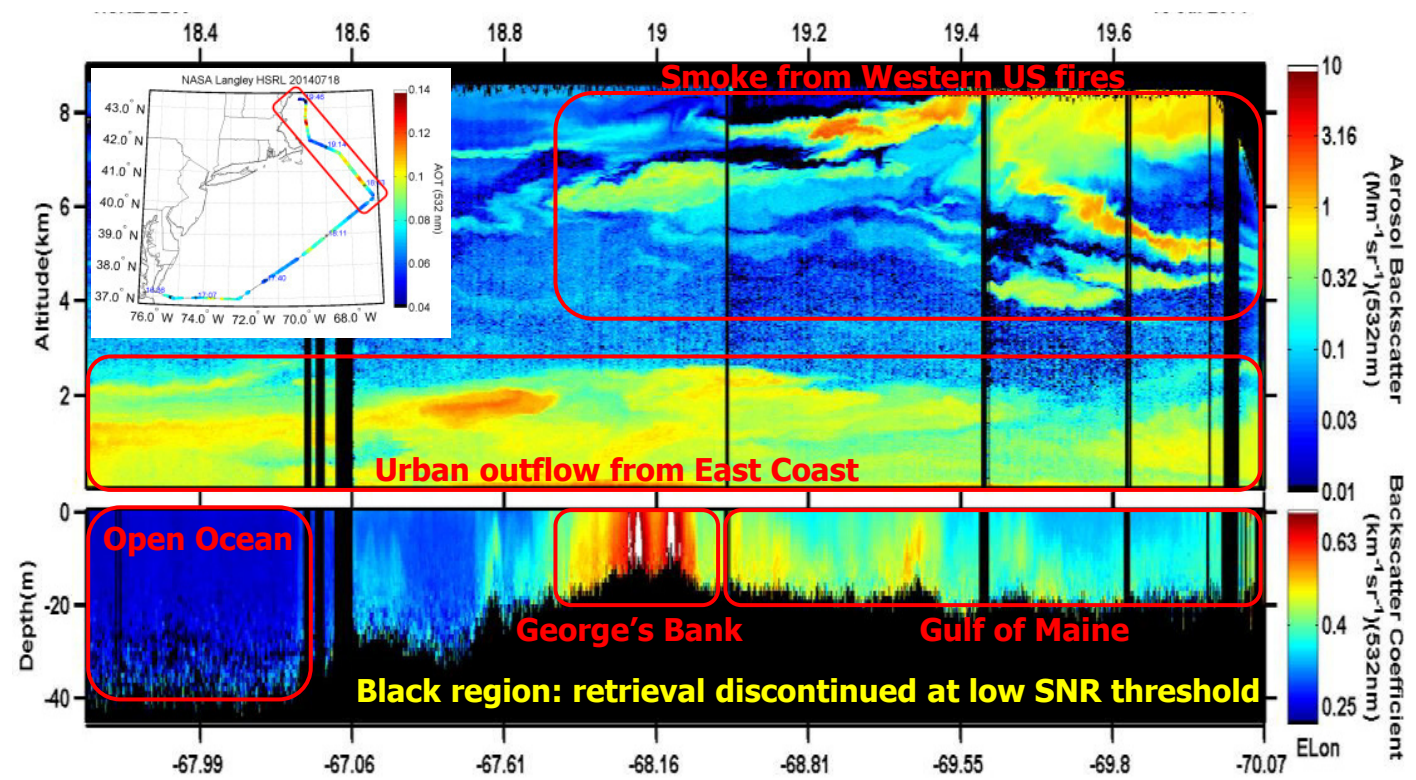

Figure 2. Particulate backscatter coefficient for the atmosphere (upper) and ocean (lower). The black regions in the ocean denote where no retrieval is performed at low SNR or is during a calibration period or aircraft turn.

retrieved by MODIS. The fundamental backscatter measurement from the lidar is the aerosol volume backscatter coefficient, $\beta(\pi)$ [3]. The fundamental retrieval from the satellite is the hemispherical particulate backscatter, $\left(b_{b p}\right)$. The lidar hemispherical backscatter is retrieved through a similar approach to that of Boss and Pegau [7] which assumes the following relationship; $\mathrm{b}_{\mathrm{bp}}=2 \pi * \chi(\theta) * \beta(\theta)$. For the lidar, It is noted that the conversion factor, $\chi(\pi)$, between the lidar $\beta(\pi)$ and the hemispherical backscatter can vary depending on size, shapes, and composition of the particle assemblage.

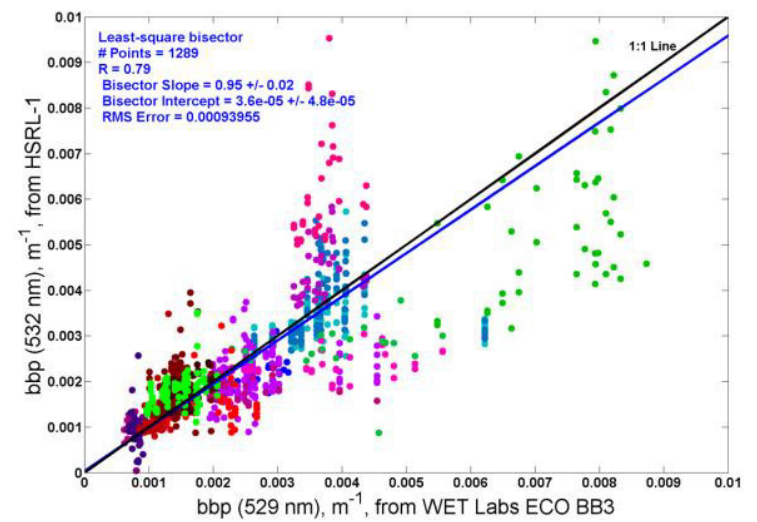

Figure 3. Comparisons of the RV Endeavor and the lidar retrieved hemispherical particulate backscatter. Colors on the graph indicate different sampling locations.
However, during the SABOR campaign we evaluated the correlation between the in situ measurements of $b_{b p}$, as outlined in [7], and the corresponding values derived from the lidar data and found a strong correlation when using $\chi(\pi)=0.5$ for the lidar as shown in Fig 3 . The slope of the correlation was 0.95 with an $\mathrm{R}^{2}=0.79$ using all profile data including the complex coastal waters and the open ocean. The data shown in this figure are in situ profile data collected during specific locations when the aircraft overflew these locations and the aircraft was within $1 \mathrm{~km}$. This result using an extensive number of comparisons is encouraging and is unprecedented in terms of using quantitative lidar measurements enabled by the HSRL technique to compare retrievals of backscatter with passive remote sensor retrievals.

Comparisons of lidar- and satellite-based retrievals of diffuse attenuation coefficients are shown if Figs. 4\&5. The flight track, color coded to show the lidar retrieval of diffuse attenuation, is shown with the MODIS QAA retrievals (4-km resolution) of diffuse attenuation [9]. A correction of the water absorption between 532nm, the wavelength the lidar measures, and the MODIS retrievals at $488 \mathrm{~nm}$ is applied. No conversion is made for the particulate spectral dependence in this case. For this flight there was a high correlation $(\mathrm{R}=0.94$, slope $=0.97)$ between the 
interpolated MODIS and lidar attenuation values (not shown). During the campaign, we composited the comparisons for all flights that had measurements from the two instruments and the correlation was impressive over a range of approximately $0.03-0.23 \mathrm{~m}^{-1}$ with an $\mathrm{R}=0.96$, slope $=1.0$ as shown in Fig 5. Similar comparisons were made with the MODIS GSM retrievals with an $\mathrm{R}=0.9$ and a slope $=0.75$.

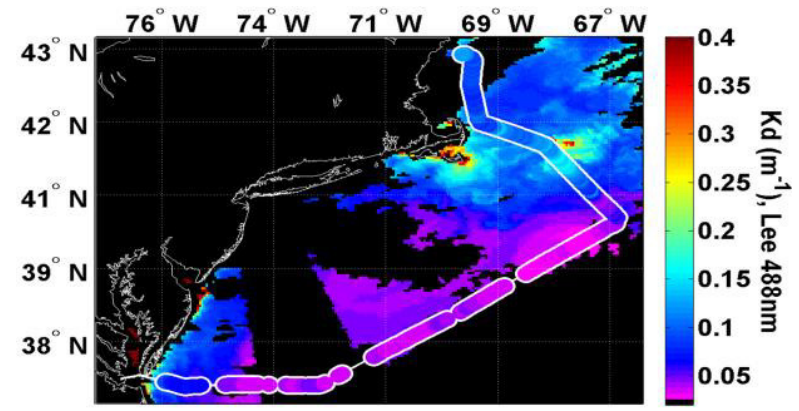

Figure 4. MODIS QAA retrieval of diffuse attenuation compared with the HSRL retrieved attenuation.

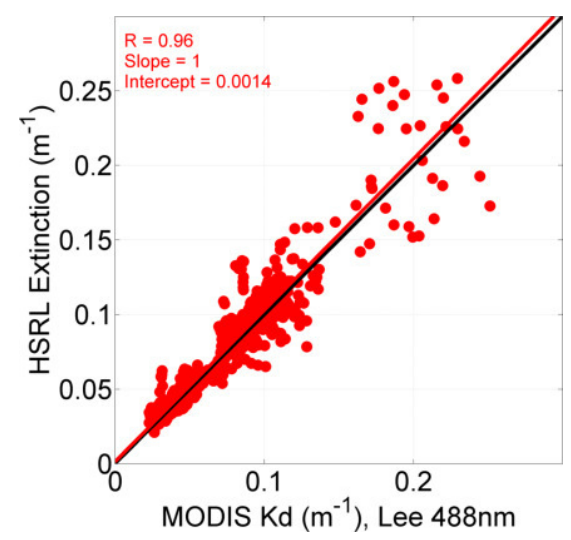

Figure 5. Correlation between lidar extinction and the MODIS QAA diffuse attenuation retrievals.

Similar to the diffuse attenuation results, comparisons were also made between estimates of particulate hemispherical backscatter $\left(b_{b p}\right)$ with no spectral corrections. Although the correlations are not as high for the backscatter data, the results offer an unprecedented set of measurements to evaluate the various ocean retrieval models. For example, the correlations of backscatter between the lidar and the satellite retrievals varied by $\mathrm{R}=0.76,0.88$, and 0.82 and slope $=1.1,1.3$, and 1.5 between the different retrieval algorithms, QAA, GSM, and GIOP [9], respectively.

\section{SUMMARY}

Results described here demonstrate that an HSRL lidar can provide both vertical profiling and direct measurements of ocean optical properties that can be used to assess and potentially improve retrievals from current and future passive ocean color sensors. The combination of these sensors will provide significant improvements in our understanding and ability to assess global ocean measurements such as particulate organic carbon and net primary productivity. It is also clear that the full benefit of lidar measurements to ocean science community has not yet been fully realized.

\section{ACKNOWLEDGEMENT}

We acknowledge the Ocean Biology and Biogeochemistry and Radiation Sciences Programs at NASA Headquarters for support. We also acknowledge the Research Services Directorate at LaRC for supporting the King Air flights.

\section{REFERENCES}

[1] Behrenfeld, M.J. and E. Boss, Beam attenuation and chlorophyll concentration as alternative optical indices of phytoplankton biomass. Journal of Marine Research, 2006. 64(3): p. 431-451.

[2] Behrenfeld, Michael J., et al. "Space-based lidar measurements of global ocean carbon stocks." Geophysical Research Letters 40.16 (2013): 4355-4360.

[3] Hair, J.W., et al., Airborne High Spectral Resolution Lidar for profiling aerosol optical properties. Applied Optics, 2008. 47(36): p. 67346752.

[5] Rogers, R. R., et al. NASA LaRC airborne high spectral resolution lidar aerosol measurements during MILAGRO: observations and validation. Atmospheric Chemistry and Physics 9.14 (2009): 4811-4826.

[6] Rogers, Raymond R., et al. Assessment of the CALIPSO Lidar $532 \mathrm{~nm}$ attenuated backscatter calibration using the NASA LaRC airborne High Spectral Resolution Lidar. Atmospheric Chemistry and Physics 11.3 (2011): 1295-1311.

[7] Boss, Emmanuel, and W. Scott Pegau. Relationship of light scattering at an angle in the backward direction to the backscattering coefficient. Applied Optics 40.30 (2001): 5503-5507.

[8] Gordon, Howard R. "Interpretation of airborne oceanic lidar: effects of multiple scattering." Applied Optics 21.16 (1982): 2996-3001.

[9] NASA Ocean Biology (OB.DAAC). Moderate Resolution Imaging Spectrometer (MODIS) Ocean Color Data, 2014.0 Reprocessing. NASA OB.DAAC, Greenbelt, MD, USA. 